\title{
Examining the relationship between the intellectual capital and the staff performance
}

\author{
Masoud Samad Zadeh*
}

Department of Management, Shahr-e-Qods Branch,Islamic Azad University, Tehran, Iran

\section{CHR ON I C LE ABSTRACT}

Article history:

Received October 28, 2013

Received in revised format

25 November 2013

Accepted 29 January 2014

Available online

February 22014

Keywords:

Intellectual capital

Performance measurement

Islamic Azad University

\begin{abstract}
This paper presents an empirical investigation to examine the relationship between the intellectual capital and staff performance of the Islamic Azad University of Qods city in Iran. The statistical universe in this research includes 8000 staff, students and faculty members of Islamic Azad University of Qods city. The proposed study takes a sample of 340 students and faculty members to evaluate staff performance. The proposed study designs a questionnaire in two parts including intellectual capital and performance measurement and Cronbach alphas for these two parts are 0.889 and 0.906 , respectively. The proposed study uses Pearson correlation test to examine the hypotheses. Based on the results of our survey, there is a positive and meaningful relationship between intellectual capital and performance of the employees.
\end{abstract}

(C) 2014 Growing Science Ltd. All rights reserved.

\section{Introduction}

During the past few years, there have been growing interests in intellectual capital, which is an important intangible asset at the current trade (Bellora \& Guenther, 2013). Chen et al. (2014), for instance, investigated changes in productivity of general insurance organizations in Malaysia over the period 2008-2011 and examined the effect of intellectual capital on changes in productivity. They first applied the Malmquist productivity index (MPI) of data envelopment analysis (DEA) and the MPI with bootstrapping method to assess changes in productivity. Then, they examined the effect of intellectual capital on changes in productivity through OLS and Tobit regressions. They reported that all but one sample organizations had experienced growth in productivity over the sample period. Moreover, the implementation of the MPI with bootstrapping method provided an effective analysis of MPI estimates. Lu et al. (2014) implemented the dynamic slack-based measure (DSBM) model to make an assessment on the performance of 34 Chinese life insurance firms over the period 20062010. They examined the relationship between intellectual capital and performance using the truncated regression approach. They reported that over the period of the study, the mean efficiency scores of life insurers were relatively stable. They confirmed that the efficiency scores of the DSBM

*Corresponding author.

E-mail addresses: hk.ie90@gmail.com (M. Samad Zadeh) 
model differ substantially from those of the traditional DEA model, which supported the use of the DSBM model. They confirmed that intellectual capitals were positively associated with firm operating efficiency. Y1ldiz et al. (2014) measured the intellectual capital through annual activity reports of banks operating in Turkey and determined whether the criteria of human capital, structural capital, and customer capital, were disclosed at various levels based on bank kinds or not. They reported that respectively, bank with private capital gave more importance to the intellectual capital.

Tsui et al. (2014) presented a Knowledge-based Intellectual Capital Extraction (KBICE) algorithm, which incorporates the technologies of computational linguistics and artificial intelligence (AI) for automatic processing of unstructured data and extraction of important IC-related information. They reported that, through the implementation of hybrid intelligent matching strategies, it would be possible to extract commonly referred IC-related information from unstructured data automatically. Abdullah and Sofian (2012) investigated the relationship between intellectual capital (IC) and corporate performance. They reported that IC is necessary to business success and performance and spiritual capital needs to be considered in IC when measuring performance. They proposed that future research should investigate the effect of the new IC on corporate performance within diverse industry for instance, to concentrate on high IC industries such as trading or services, finance or technology.

\section{Research purposes}

This paper presents an empirical investigation to examine the relationship between the intellectual capital and staff performance of the Islamic Azad University of Qods city in Iran. The statistical universe in this research includes 8000 staff, students and faculty members of Islamic Azad University of Qods city. We assume the population follows a normal distribution. Therefore we could use the following formula to calculate the minimum number of sample size,

$n=\frac{N \times z_{\alpha / 2}^{2} \times p \times q}{\varepsilon^{2} \times(N-1)+z_{\alpha / 2}^{2} \times p \times q}$,

where $N$ is the population size, $p=1-q$ represents the yes/no categories, $z_{\alpha / 2}$ is CDF of normal distribution and finally $\varepsilon$ is the error term. Since we have $p=0.5, z_{\alpha / 2}=1.96$ and $N=8000$, the number of sample size is calculated as $n=340$. The proposed study of this paper develops one main hypothesis and three hypotheses as follows,

Main hypothesis:

There is a positive and significant relationship between intellectual capital and staff performance.

Secondary hypotheses:

1. There is a positive and significant relationship between human capital and staff performance.

2. There is a positive and significant relationship between structural capital and staff performance.

3. There is a positive and significant relationship between communicational capital and staff performance.

The questionnaire is designed in Likert scale, which consists of 37 questions for measuring intellectual capital and the study has been accomplished among students and faculty members in Islamic Azad University-Shahr-e- Qods branch we used relative-categorical sampling method. Table 1 demonstrates details of the personal characteristics of the participants. 
Table 1

Personal characteristics of the participants

\begin{tabular}{lll}
\hline Category & Population & Samples \\
\hline Student & 16300 & 277 \\
Staff & 222 & 89 \\
Faculty members & 163 & 63 \\
\hline Sum & 16685 & 429 \\
\hline
\end{tabular}

Cronbach alpha for the first questionnaire for intellectual capital with 37 questions and performance measurement with 44 questions are 0.889 and 0.906 , respectively. Therefore, the overall questionnaires are confirmed. We also need to find out whether the data are normally distributed or not and this is accomplished by Kolmogorov-Smirnov test and Table 2 shows details of our findings.

Table 2

The results of Kolmogorov-Smirnov

\begin{tabular}{|c|c|c|c|}
\hline & & Intellectual capital & Performance \\
\hline \multicolumn{2}{|c|}{$\mathrm{N}$} & 429 & 340 \\
\hline \multirow[t]{2}{*}{ Normal Parameters $^{\mathrm{a}}$} & Mean & 19.5234 & 66.2092 \\
\hline & Std. Deviation & 5.25882 & 15.81439 \\
\hline \multirow{3}{*}{$\begin{array}{l}\text { Most Extreme } \\
\text { Differences }\end{array}$} & Absolute & .060 & .055 \\
\hline & Positive & .060 & .055 \\
\hline & Negative & -.046 & -.033 \\
\hline \multicolumn{2}{|c|}{ Kolmogorov-Smirnov Z } & 1.246 & 1.053 \\
\hline \multicolumn{2}{|c|}{ Asymp. Sig. (2-tailed) } & .090 & .218 \\
\hline
\end{tabular}

As we can observe from the results of Table 2, intellectual capital and performance both are normally distributed. Therefore, we can use Pearson correlation ratio to examine the hypotheses of the survey.

\section{The results}

In this section, we present details of our findings on testing various hypotheses of the survey based on Pearson correlation ratio.

\subsection{The main hypothesis: The relationship between employee performance and intellectual capital}

Table 3 shows details of Pearson correlation test between these two components.

\section{Table 3}

The summary of Pearson correlation test

\begin{tabular}{llcc}
\hline & & Performance & Intellectual capital \\
\hline Performance & Pearson correlation & 1 & $.872^{* *}$ \\
& One domain level of significance & .000 & 417 \\
\hline Number & 340 & 1 \\
\hline & Pearson correlation & $.872^{* *}$ & .000 \\
& One domain significant level & 405 & 429 \\
\hline
\end{tabular}

\footnotetext{
**. Correlation is significant at the 0.01 level (1-tailed).
} 
The results of Table 3 clearly indicate that there is a positive and meaningful relationship between intellectual capital and performance when the level of significance is one percent. Therefore, the main hypothesis of the survey has been confirmed.

\subsubsection{The first sub-hypothesis: The relationship between employee performance and human capital}

The first sub-hypothesis of this survey investigates the relationship between employee performance and human capital. Table 4 demonstrates the summary of our findings.

\section{Table 4}

The summary of Pearson correlation between employee performance and human capital

\begin{tabular}{llcc}
\hline & & Performance & Human capital \\
\hline Performance & Pearson correlation & 1 & $.622^{* *}$ \\
& One domain level of significance & & .000 \\
& Number & 340 & 417 \\
\hline Human capital & Pearson correlation & $.622^{* *}$ & 1 \\
& One domain level of significance & .000 & 429 \\
& Number & 405 & \\
\hline
\end{tabular}

**. Correlation is significant at the 0.01 level (1-tailed).

The result of Table 4 confirms the first sub-hypothesis and we can conclude that there is a positive and meaningful relationship between employee performance and human capital when the level of significance is one percent.

3.1.2. The second sub-hypothesis: The relationship between employee performance and structural capital

The second sub-hypothesis of this survey investigates the relationship between employee performance and structural capital. Table 5 presents the summary of our findings.

Table 5

The summary of testing the second sub-hypothesis

\begin{tabular}{llcc}
\hline & & Performance & structural capital \\
\hline Performance & Pearson correlation & 1 & $.872^{* *}$ \\
& One domain level of significance & .000 & 417 \\
\hline Structural capital & $\mathrm{N}$ & 340 & 1 \\
& Pearson correlation & $.872^{* *}$ & .000 \\
& One domain level of significance & 405 & 429 \\
\hline
\end{tabular}

**. Correlation is significant at the 0.01 level (1-tailed).

Based on the results of Table 5, we can conclude that there is a positive and meaningful relationship between employee performance and communicational capital.

\subsubsection{The third sub-hypothesis: The relationship between employee performance and} communicational capital

The third sub-hypothesis of this survey investigates the relationship between employee performance and communicational capital. Table 6 presents the summary of our findings. 
Table 6

The summary of testing the second sub-hypothesis

\begin{tabular}{llcc}
\hline & & Performance & Communicational capital \\
\hline Performance & Pearson correlation & 1 & $.828^{* *}$ \\
& One domain level of significance & & .000 \\
& $\mathrm{~N}$ & 340 & 417 \\
\hline Communicational capital & Pearson correlation & $.828^{* *}$ & 1 \\
& One domain level of significance & .000 & 429 \\
& $\mathrm{~N}$ & 405 & \\
\hline
\end{tabular}

**. Correlation is significant at the 0.01 level (1-tailed).

Based on the results of Table 6 , we can conclude that there is a positive and meaningful relationship between employee performance and communicational capital.

\section{Conclusion and suggestions}

In this paper, we have presented an empirical investigation to study the relationship between employee performance and human capital. Using Pearson correlation ratio, the study has examined the main hypothesis as well as three sub-hypotheses of the survey. The results of our survey has concluded a positive and meaningful relationship between employee performance and human capital $(\mathrm{r}=0.622$, Sig. $=0.000)$, a positive and meaningful relationship between employee performance and structural capital $(r=0.872$, Sig. $=0.000)$ and finally, a positive and meaningful relationship between employee performance and communicational capital $(\mathrm{r}=0.828$, Sig. $=0.000)$. We have also performed a detailed discussion on how to improve the performance of employee and the following suggestions have been reached.

1. It is necessary to increase welfare and official possibilities at the universities by establishing offices for staff, faculty members and students to provide better working environment.

2. Except to some official automation systems, most university activities are in forms of paperbased system. Therefore, development and encouraging activities by office automation in different sections of educations, researches, etc. are necessary.

3. Access to high-speed internet for the entire faculty members and students is not available. A high quality internet access could help university professors as well as students do their research activities much easier, which improve the university productivity.

4. Lowering the time of expectation for responding to staff, faculty members and students of this unit.

5. Lowering the rate of doing official affaires at the universities and applying university programs based on the time management in university.

6. Paying attention to students and faculty members' satisfaction from educational services and offering welfare and educational services based on their expectations.

7. Paying attention to suggestions and staff criticisms, faculty members and students considering appropriateness of the entire programs and university designs. 


\section{Acknowledgment}

This article is derived from a research design entitled as "the strategies for increasing intellectual capital in Islamic Azad University-Shahr-e- Qods branch" and the researcher appreciates the supports of this university.

\section{References}

Abdullah, D.F., \& Sofian, S. (2012). The relationship between intellectual capital and corporate performance. Procedia - Social and Behavioral Sciences, 40, 537-541.

Bellora, L., \& Guenther, T.W. (2013). Drivers of innovation capital disclosure in intellectual capital statements: Evidence from Europe. The British Accounting Review, 45(4), 255-270

Chen, F.C., Liu, Z.J., \& Kweh, Q.L. (2014). Intellectual capital and productivity of Malaysian general insurers. Economic Modelling, 36, 413-420.

Lu, W.M., Wang, W.K., \& Kweh, Q. L. (2014). Intellectual capital and performance in the Chinese life insurance industry. Omega, 42(1), 65-74.

Tsui, E., Wang, W.M., Cai, L., Cheung, C.F., \& Lee, W.B.(2014). Knowledge-based extraction of intellectual capital-related information from unstructured data. Expert Systems with Applications, 41(4), 1315-1325

Y1ldı,, S., Meydan, C., \& Güner, M. (2014). Measurement of intellectual capital components through activity reports of companies. Procedia - Social and Behavioral Sciences, 109(8), 614-621. 